\title{
《I
}

\section{Lição: Algumas reflexões sobre agenciamento e atividade fora do sistema comercial. ${ }^{1} 2$}

Lesson: Some Thoughts on Agency and Activity Outside of the Commercial System

\section{Harrell Fletcher}

Harrell Fletcher received his BFA from the San Francisco Art Institute and his MFA from California College of the Arts. He studied organic farming at UCSC and went on to work on a variety of small Community Supported Agriculture farms, which impacted his work as an artist. Fletcher has produced a variety of socially engaged collaborative and interdisciplinary projects since the early 1990's. His work has been shown at SFMOMA, the de Young Museum, the Berkeley Art Museum, the Wattis Institute, and Yerba Buena Center for the Arts in the San Francisco Bay Area, The Drawing Center, Socrates Sculpture Park, The Sculpture Center, The wrong Gallery, Apex Art, and Smackmellon in NYC, DiverseWorks and Aurora Picture show in Houston, TX, PICA in Portland, OR, CoCA and The Seattle Art Museum in Seattle, WA, Signal in Malmo, Sweden, Domain de Kerguehennec in France, The Tate Modern in London, and the National Gallery of Victoria in Melbourne, Australia. He was a participant in the 2004 Whitney Biennial. Fletcher has work in the collections of MoMA, The Whitney Museum, The New Museum, SFMOMA, The Hammer Museum, The Berkeley Art Museum, The De Young Museum, and The FRAC Brittany, France. From 2002 to 2009 Fletcher co-produced Learning To Love You More, a participatory website with Miranda July. Fletcher is the 2005 recipient of the Alpert Award in Visual Arts. His exhibition The American War originated in 2005 at ArtPace in San Antonio, TX, and traveled to Solvent space in Richmond, VA, White Columns in NYC, The Center For Advanced Visual Studies MIT in Boston, MA, PICA in Portland, OR, and LAXART in Los Angeles among other locations. Fletcher is an Associate Professor of Art and Social Practice at Portland State University in Portland, Oregon.

Fonte: http://www.harrellfletcher.com/?page_id=37

TUTOR: Harrell Fletcher

Nasceu / Vive e Trabalha: 


\section{7) Ryvsra \\ A APOTHEKE}

- Santa Maria, CA, 1967

- Portland, OR

Treinamento/Formacão:

- Certificação Horticultura Ecológica. Universidade da Califórnia, Santa Cruz, 1996.

- MFA (Master of Fine Arts) Interdisciplinar, Escola Superior de Artes e Ofícios da Califórnia, Oalkland, 1994

- BFA (Bacharel Fine Arts) Fotografia. Instituto de Arte de São Francisco. 1990.

\section{Postos de Ensino/ locais onde trabalhou como professor}

- Professor Associado da Prática Artística e Social da Universidade Estadual de Portland, OR, 2009 - até o presente momento

- Professor Assistente de Prática Social e Artística da Universidade Estadual de Portland, OR, 2004-2009

- Instrutor de Escultura, Cooper Union, Nova York, 2004

- Instrutor, Projeto Especial, Escola de Arte de Hartford, West Hartford, CT, 2003

- Instrutor, Seminário de Pós-Graduação Interdisciplinar.

Escola Superior de Artes da Califórnia, São

Francisco, 2001

\section{Trabalhos Relevantes:}

- The American War (A Guerra Americana), 2005

- I'll Follow You, ( Eu Seguirei Você), 2005

- With Our Own Little Hands Summer, (Com Nossas Próprias Pequenas Mãos no Verão), 2005

- If I Wasn't Me I Wouldn't Be You, ( Se eu não fosse eu, eu não seria você), 2003

- Hello There Friend, ( Olá Há Amigo),2003

- The Sound We Make Together, ( O Som que Nós Fazemos Juntos), 2003

- Everyday Sunshine, (Todos os dias a luz do sol brilha), 2001

- Saying I Love You or Something Like That, ( Dizendo Eu Amo Você ou Alguma Coisa como isto), 2000

\section{Prêmios :}

- Prêmio de Engajamento Cívico, Universidade Estadual de Portland, OR, 2009

- Prêmio Alpert em Artes Visuais, Santa Mônica, CA, 2005 


\section{VI.}

- Prêmio Área da Baía, São Francisco, 1994

\section{Exposições recentes individual ou coletiva:}

2014: To a Lifetime of Meaningful Encounters ( Para um Tempo de Vida de Significativos Encontros), ( Com Molly Sherman e Nolan Calish) Museu de Matisse, Le Cateau-Cambrésis, França // 2013: The Best Things in Museus are the Windows (As Melhores Coisas nos Museus São as Janelas), Exploratorium, São Francisco-CA //

2012: Before and After 1565: A Participatory Exploration of St. Augustin's Native American History ( Antes e Depois de 1565: A Exploracão Participativa da História do nativo americano ST Augustin), Crisp-Ellert Art Museum, St Augustin, FL // The Hammer Yearbook, (With Adam Moser) The Hammer Museum, Los Angeles//

2011: Active Engagment, (Engajamento Ativo), Idea space, Colorado Springs, CO //

2010: The Sound We Make Together ( O SOm que Nós Fazemos Juntos)

Galeria Nacional de Vitória, Melbourne, Austrália // My War ( Minha Guerra), Fundação de Arte e Tecnologia Criativa, Liverpool, UK //

2009: Made in India (Feito na Índia), Galeria de Arte de Mississauga, Canadá

2008: Born Out of Pleasure ( Nascido fora do prazer), The Power Plant, Toronto//

2007: The American War (A Guerra Americana), Centro Contemporâneo de Arte de Atlanta, GA e LAXART, Los Angeles // Learning to Love You More (Aprendendo a Amar Mais Você) com Miranda July, MU, Eindhoven-Holanda// Come Together (Venha Junto), Henry Galeria de Arte, Universidade de Washington, Seattle //

2006: Where I Lived and What I Lived For ( Onde Eu Morava e Para O quê Eu Vivi), Domaine de Kerguehennec Centro de Arte, Bignan, França // Some translations (Algumas Traduções), In Situ, Paris//

2005: With Our Little Hands ( Com Nossas Pequenas Mãos), The Wrong Gallery, Nova York

\section{Recentes Exposições em Grupo:}

2014: The Parliament of Things or an Exibition that Loses Itself ( O Parlamento de Coisas ou a Exibição do que se perde), CAFAM Biennale, Academia Central de Belas Artes Museu, Beijing //

2013: Past is Present (Passado é Presente), com Katherine Ball, MOCA, Detroit, MI // 


\section{Rerysta \\ A APOTHEKE}

2012: The Shaping of New Visions: Photography, Film, Photobook ( A Configuração das Novas Visões: Fotografia, Filme, Photobook) MoMa, Nova York // The Northwest Biennial, Tacoma Art Museum, WA // Wide Open School (Ampla Escola Aberta), Hayward Gallery, Londres //

2010: The More Things Change( Quanto Mais as Coisas Mudam), SFMOMA, São Francisco //

2009: The New Normal ( O Novo Normal), Pomona Escola Superior Museu de Arte, Claremont, CA // Assume Nothing: New Social Practice (Assumir Nada: A Nova Prática Social), A Galeria de Arte da Grande Vitória, BC //

Land Wars ( Guerras Terrestres), Te Tuhi Centro Para as Artes, Pakuranga, Auckland, Nova Zelândia //

2007: Memorial to the Iraq War ( Memorial para a Guerra do Iraque), ICA, Londres//

2006: Phantom Captain: Art and Crowdsourcing, Apexart, Nova York // Critical Translations; Art That Examines/ Our Social World, Universidade de Minessota, MN//

2004: Whitney Biennial( Whitney Bienal), Whitney Museu de Arte Americano, Nova York

Lição: Alguns pensamentos/ ideias sobre Agência e Atividade fora do Sistema Comercial. (Lesson: Some Thoughts on Agency and Activity Outside of the Commercial system)

Eu saí para jantar com um de meus alunos de graduação outro dia e ele me perguntou que conselho eu daria a ele como um artista emergente. Você tem que entender que um programa de Pós Graduação que eu segui não é um programa normal MFA (Fine Arts Master), então ele já estava começando com uma estrutura diferente da maioria dos estudantes de MFA. Nosso MFA é focado na Arte e Prática Social. O que significa exatamente é abrir para interpretar e debater mesmo dentro do próprio programa, não para mencionar no contexto da minoria de prática social tipo programas MFA para outras escolas e as várias outras instituições, museus, residências, fundações, etc que tem recentemente focado algumas das suas energias em mais atividades de arte engajadas socialmente. Eu penso que é seguro dizer que muitas destas iniciativas enfatizam o tradicional trabalho de estúdio e o sistema de galeria comercial, ao invés de promover mais colaborativamente, site specific e frequentemente menos ou nenhum objeto orientando o trabalho.

Encarando esta questão eu me deparei com uma resposta. Os vinte anos de minha própria carreira e caminhada tem sido altamente não ortodoxas, e por esta razão são difícieis de usar um modelo em qualquer exata maneira, embora deve haver alguns conceitos básicos que são de uso no período antes do advento do uso geral da internet. Era muito mais dificil 


\section{W.}

procurar por práticas de arte que estavam começando a ser interessantes para mim ao invés de usar uma procura instantânea do Google. Eu vagava pela arte entre corredores de livrarias e lojas de livros, ia a quaisquer eventos, palestras e exibições disponíveis para mim e conversava com pessoas que pareciam ter informação do jeito que eu estava procurando. Minhas descobertas significantes foram poucas e distantes entre elas, mas descontroladamente impactantes em mim como um artista em desenvolvimento. Um pouco das pessoas naquela categoria e de recente e importante influência são Wendy Ewald e o seu livro Retratos e Sonhos, os quais foram criados na colaboração com o grupo de crianças Appalachien no Eastern Kentucky; John Malpede e os Los Angeles Poverty Department, o grupo de teatro ele fundou com pessoas do skid Row; Jim Goldberg e seu livro Rich and Poor (Rico e Pobre), o qual foi documentado e trabalhado com pessoas da cidade de São Francisco de muito baixo e alto grupos econômicos STRATA em 1980; Larry Sultan e seu projeto de livro fotográfico Pictures From Home( Fotos de Casa) sobre seus parentes, a história dele e sua dinâmica pessoal com eles; a vasta coleção de muitos vídeos pessoais de George Kucher's, especialmente o Weather Diaries ( Diários do tempo), os quais foram lançados a cada verão em uma pequena cidade de Oklahoma; um Group Material (Grupo Material) e a exibição de suas People's Choice (Escolhas pessoais), onde eles colecionaram objetos significativos dos residentes que moravam na vizinhança em Lower, East Side, nos quais estavam localizados nas vitrines das galerias. Eu estava também muito interessado em proponentes de educação alternativa como John Holt, A.S.Neill e Miles Horton, e back-to-the-land (de volta a terra) e figuras urbanas agriculturais, incluindo Helen e Scott nearing, Alan Chadwick e Catherine Sneed.

De fato, uma coisa incrivelmente importante para qualquer um interessado em desenvolver uma carreira de qualquer tipo é encontrar um conjunto de exemplos que podem ser usados para dar um ponto de partida. Educação padrão geralmente resulta em modelos genéricos e padrão, e por esta razão é necessário procurar fora de uma ortodoxia e determinadas pessoas, práticas e projetos os quais você está individualmente desenhando e se entusiasmando. No meu próprio trabalho, encorajo estudantes a olhar além mesmo da disciplina de arte e em vez disso, em outras áreas de estudo e aplicação que poderiam incluir matérias como planejamento urbano, estudos negros, resolução de conflitos, história pública, sociologia, etc...

Anos depois de conseguir meu próprio grau em MFA ( Master Fine Arts) eu decidi voltar para escola e estudar agricultura orgânica. Eu fiz isto como parte de um programa incomum na Universidade de Califórnia em Santa Cruz (UCSC) chamada The Apprenticeship in Ecological Horticulture (A 


\section{A 1 APOTHEKE}

Aprendizagem em Horticultura Ecológica) e Sustainable Food Sistems (Sistemas de Alimentação Sustentável). Isto foi somente um programa de seis meses, mas isto mudou dramaticamente minha vida e prática artística. Haviam quarenta aprendizes e nós todos vivíamos em tendas na fazenda, os quais eram no campus da UCSC. Nós aprendemos fazendo em uma variedade de muitas maneiras, incluindo não somente o crescimento de vegetais e frutas, mas também distribuindo-os em pequenas escalas. Eu entendi que haviam muitas similaridades entre meus colegas estudantes na escola de arte e na escola da fazenda - por exemplo, havia um impulso de criação e divisão em um pouco das maneiras alternativas. Mas haviam também diferenças maiores. A Escola de Arte parecia encorajar a competição e territorialidade embora houvesse um foco maior na "originalidade" e novidade. As estruturas seguidas eram convenções muito rígidas e pareciam ser largamente limitadas de muitas maneiras. Escolas de fazenda não colocam ênfase na novidade, apenas hibridizam o que quer que pareça útil; tradição era importante, mas confiando na convenção, somente acontecendo onde faria sentido. Cooperação era muito mais importante do que competição e havia uma compreensão holística da importância de não apenas fazer um produto, mas também pensando sobre como conseguir que o produto a se consumir numa localizada recíproca moda. Depois de terminar o programa, eu trabalhei em muitas pequenas fazendas e comecei a usar uma variedade de aspectos dos quais eu tinha aprendido da fazenda na minha arte e prática educacional.

Eu cresci numa pequena cidade na Califórnia, quando a oportunidade apresentou-se para viver em uma área urbana. Escolhi a Área da Baía de São Francisco sobre Los Angeles. Depois de dez anos lá, indo para a escola e fazendo projetos com quase todas as organizações de arte da região, eu decidi mudar não para a cidade de Nova York, como era a trajetória esperada de um artista local de sucesso, mas ao invés disso, fui para Portland Oregon, a qual naquele tempo não tinha nada das propagandas publicitárias relacionados com o recentemente Desenvolvido FOOD-CART e programa de TV badalados. Muitas das pessoas do mundo da arte que eu conhecia, consideraram isto um movimento para uma carreira suicida, mas por então eu tinha desenvolvido uma aversão para muitos aspectos do mundo da arte e estava amplamente de bem com a ideia de que eu poderia vagarosamente desaparecer na obscuridade. Como isto acabou, minha carreira continuou, em um muito moderado, mas em um consistente ritmo, desenvolvendo-se ao longo dos próximos vinte anos depois de fazer de Portland a base da minha casa, possivelmente em uma maneira de mais sucesso do que eu poderia ter se eu tivesse seguido o mais tradicional padrão de relocação de Los Angeles para Nova York. 


\section{A.}

Há umas poucas razões para isto, as quais também se aplicam para outras pessoas que querem uma carreira funcional como um artista, mas não querem viver em um cubo do mundo da arte. O maior fator, o qual é facilmente esquecido em retrospectiva, é a popularização da rede (web). No momento em que eu me mudei para Portland, poucos tiveram suas próprias presenças na rede e ao invés de necessitarem de representações comerciais de galerias para conseguir a repercussão sobre seus trabalhos. A assistência de galerias pode naturalmente ser de muita ajuda especialmente se o que você quer fazer como um artista é construir objetivos para vender, mas há agora vários exemplos de artistas que construiram a carreira para eles mesmos sem um relacionamento com uma galeria comercial, frequentemente fazendo um trabalho baseado em localização e então mostrando documentação na web, aconteceu de obterem sorte. Um web designer chamado Yuri Ono aproximou-se de mim em torno do momento que eu estava mudando para Portland e sugeriu fazer um website para mim. Eu estava em dúvida, mas dei a ele a experiência de fazer e acabou sendo muito significativo o desenvolvimento de minha carreira. De repente, curadores e pessoas interessadas através do país e em outras localidades por volta do mundo foram capazes de ver o que, até certo ponto, tinha sido um conjunto de trabalhos feitos amplamente como projetos de site-specific na Área da Baía. Algumas daquelas pessoas começaram a enviar e-mails para mim, solicitando-me para fazer shows, palestras e projetos variados e as oportunidades pareciam multiplicar-se. Este foi um tempo antes do Facebook, You Tube mesmo E_FLUX?, até então as possibilidades daquelas plataformas não tinham sido consideradas. A infinidade dos recursos baseados na Web existentes agora oferecem mesmo grande potencial de visibilidade fora do sistema comercial de arte do que eram avaliados quando eu estava começando.

Outro resultado positivo da minha movimentação para uma cidade não do mundo da arte era que haviam poucos artistas dos quais as pessoas eram conscientes lá, então quando um curador veio para a cidade eu estava usualmente na sua lista daqueles para ele encontrar. Adicionalmente, o custo de viver era mais baixo. Eu poderia proporcionar-me comprar uma casa. Eu era capaz de encontrar um trabalho para ensinar e organizações de artistas locais estavam interessadas em trabalhar comigo. Possibilidades similares aguardam outros artistas que escolhem viver fora dos caminhos locais se eles estão esperando essa chance. Eu tenho a melhor de ambas as palavras porque eu viajei muito a trabalho e ainda sou capaz de ficar em contato com pessoas e eventos que acontecem fora de Portland.

Meu senso de como minha própria carreira realmente se desenvolveu embora esteja tão distante como escola de graduação, eu praticamente parei de fazer objetos em estúdios 


\section{Rerysta \\ A APOTHEKE}

com a intenção de vendê-los em galerias, e ao invés de ter começado a fazer uma grande variedade de projetos que eram site-specific, participativos e públicos. Eu não esperei por um curador ou proprietário de galeria para dizer que o meu trabalho era válido e pronto para ser mostrado; ao invés, eu apenas comecei fazendo o trabalho na escola e em minha vizinhança os quais eu estava totalmente em controle não apenas o "trabalho de arte" no senso de pintar ou esculpir, mas em termos da seleção ou criação de um contexto que o trabalho estava sendo feito, sabendo que haveria uma audiência específica e pensando sobre coisas como posters associados, publicações, eventos etc. Eu era capaz de saber que o trabalho que eu estava fazendo atualmente seria e teria uma função na sociedade. Na escola de graduação, eu fiz coisas como criar minha própria livraria e minha própria galeria na vizinhança em uma loja de construção vazia, mas eu também fiz projetos na escola fundamental local. Em empresas existentes e nas ruas de várias maneiras. Fazendo o trabalho público e fazendo em colaboração com pessoas locais nas matérias do interesse deles, havia um investimento automático no que estava sendo feito. Não estava sendo colocado meu trabalho de arte em um espaço de galeria em uma locação obscura e então esperando pessoas que queriam vir e apreciar, ao contrário, eu fiz isto onde as pessoas já estavam e fiz isto com eles tanto que havia fácil acesso e um senso de envolvimento pessoal. Como um resultado, o público, tanto local como fora da cidade, tomaram conhecimento e desenvolveram interesse no trabalho.

Alguma coisa que eu sempre tentei ter em mente é a ideia que um artista é alguém que consegue fazer o que quer que ele queira fazer. Odontologia é realmente interessante, mas se você tornar-se um dentista, você terá ampla necessidade de trabalhar sobre os dentes de forma tradicional, pelo menos profissionalmente. A maior parte das outras carreiras parecem operar em maneiras similares, mas artistas podem, como parte de sua prática profissional, decidir fazer um trabalho sobre qualquer assunto e de qualquer forma. Ser pago para fazer este trabalho é sempre outra questão e a que parece dirigir artistas e escolas de arte em direção ao sistema comercial de galerias, a necessidade deles por produto e todos os elementos adicionais que prosseguem junto com isso revistas de arte, feiras de arte, pessoas ricas etc. Assim, portanto se não é tão estranho que artistas podem fazer qualquer coisa que querem, muitos deles escolhem cronometrar o seu tempo em um estúdio fazendo pinturas e outros objetos vendáveis (mesmo se eles nunca mostraram ou venderam estes objetos). Tentei realmente com esforço liberar-me deste conjunto de condições e ao invés disso questionei repetidamente o que eu ultimamente valorizava, e o que eu queria fazer para desperdiçar o meu tempo. 


\section{Rerysta A APOTHEKE}

Por causa da natureza do meu trabalho e meu próprio histórico de projetos, eu sou frequentemente afortunado de estar em uma posição onde uma instituição (usualmente uma escola ou um centro de arte ou museu) irão comissionar-me a fazer um novo projeto para eles. Isto é compreensível que eu poderia fazer qualquer coisa de forma diferente do que eu tinha feito antes, que havia provavelmente de ser colaborativo e participativo em aspectos, que eu provavelmente teria no componente educacional nos quais

seria o único a aprender e que poderia não ser de todo qualquer objeto produzido. No passado, estes projetos haviam incluído fazer um filme em um centro de idosos com as pessoas lá, baseado em Ulisses de James Joyce; produzindo uma escultura pública usando as ideias de um trabalho colaborativamente com crianças, andando com um grupo de pessoas por dias, aprendendo sobre a história e ciência de seu ambiente; criando uma participação geográfica, aprendendo experiência de uma loja de doces internacional; recriando um museu de guerra do Vietnã em vários locais dos Estados Unidos; e um amplo número de outras atividades que estão somente conectadas com meu desejo de aprender e apreciar o conhecimento, as habilidades e a cultura locais.

Estes projetos e minha prática como um todo são muito subjetivos e pessoais para mim. Eu não quero dizer a eles para pensarem em modelos específicos para outros artistas usarem, mas eu suponho que eu gostaria de sugerir através de minha própria história e trabalho atual é que artistas podem tomar uma responsabilidade individual e atividades no que diz respeito a como e de quais maneiras eles concebem e produzem seus próprios trabalhos.

\section{Referências Literárias}

Ewald, Wendy. Portraits and Dreams. New York: Writers and Readers Publishing, 1985

Eu descobri uma cópia de Portraits and Dreams (Retratos e Sonhos) na biblioteca da Universidade Estadual de Humboldt quando eu era estudante universitário pelos idos dos anos 1980. O livro me surpreendeu totalmente e redirecionou meu trabalho como artista e professor. Ewald viveu em uma parte bastante rural na parte oriental de Kentucky e trabalhou com um grupo escolar de crianças por alguns anos os quais eles fizeram sobre suas próprias vidas e mundos interiores. Os resultados são verdadeiramente assustadores.

Freire, Paulo e Myles Horton. We make the Road by Walking. Philadelphie: Temple University Press, 1990.

Eu corri atrás de We Make the Road by Walking (Nós Fazemos a Estrada Andando), em um ponto mais tarde da minha vida do que 


\section{Rerysta \\ A APOTHEKE}

os outros livros, mas era igualmente importante para mim. Muitas pessoas estão familiarizadas com Freire e o seu trabalho na América do sul, mas menos conhecido (embora igualmente não mais incrível para mim) é Miles Horton e sua Tennesses - Organização baseada na Escola Folclórica Highlander. Highlander teve muitas direções, mas esteve sempre operado em uma forma DE- AUTHORITISED ( sem autoridade ??) e focando em uma variedade de questões políticas e sociais - era na maioria uma protuberância de atividades durante o movimento dos Direitos Civis. O livro foi criado de uma maneira interessante demais que eu tenho replicado em algumas ocasiões. Foi gravada uma conversa que Freire e Horton tiveram juntos e que mais tarde foi transcrita e colocada na forma de livro.

Holt, John. How Children Learn, Revised Edition. New York: Delacort Fress/Seymour Lawrance, 1983.

Adquiri este meu primeiro, de muitos livros de John Holt, em uma feira de livros anarquistas em Londres, quando eu estava na graduação, estudando no exterior por um semestre. Foi também muito importante para mim na minha compreensão das alternativas educacionais e direitos das crianças. O outro aspecto do livro pelo qual fui atingido é que o livro de 1983 é uma edição revisada do original de 1967 e Holt escreveu comentários (frequentemente críticas) nas margens do livro sobre o seu texto escrito anteriormente. Pensei que foi uma ideia interessante re-examinar o seu próprio trabalho e trazer o processo à público.

Nearing, Helen and Scott Nearing. Living the Good Life: How to Live Sanely In a Troubled World. Mainer Social Sciences Institute, 1954 .

Eu tropecei no The Good Life ( A Boa Vida) em uma livraria em Arcata, CA, quando eu estava no começo dos meus vinte anos. É a história de um recente casal "Back to the Land" ( De Volta para a Terra) e sua específica maneira de organização e efetivamente morando em um estilo de vida alternativo. Este livro, ao longo dos outros tantos, conduziu-me a agricultura orgânica, a qual teve um impacto maior na minha prática artística.

Neill, A. S. Summerhill: A Radical Approach to Child Rearing. New York: Hart Publishing Company, 1960.

Eu comprei uma cópia do Summerhill na mesma feira de livros de Londres. É sobre uma escola alternativa na Inglaterra na qual as crianças são dados os mesmos direitos do que os adultos. Eu recordo a minha leitura da primeira vez e a confirmação de um sentimento de todo o meu próprio senso de infância e dos erros de uma educação tradicional que eu experimentei. As ideias no 


\section{R| Revrsta \\ A) APOTHERE}

livro tiveram impacto em um monte das minhas maneiras de ensinar e nos projetos participativos ao longo dos anos.

1 Este texto foi inicialmente publicado no Livro: Akademie X Lessons In Art + Life da Editora Phaidon, 2015. Título original: Lesson: Some Thoughts on Agency and Activity Outside of the Commercial system. O autor autorizou a tradução deste texto para o português com finalidade acadêmica.

Tradução: Mestranda Márcia Amaral Figueiredo. 